\title{
Covid-19, the WHO, and the apparent collapse of traditional medical research ethics
}

\author{
GODFREY B TANGWA
}

\begin{abstract}
On January 14, 2021, a WHO Ad Hoc expert group published an article in the highly influential The New England Journal of Medicine, titled: "Placebo-Controlled Trials of Covid-19 Vaccines Why We Still Need Them" justifying the use of placebo in further trials of Covid-19 vaccines, even after purported efficacious vaccines have become available. Medical research involving human beings ought to conform strictly to principles, rules and procedures established since the Nuremberg Code (1947), especially as elaborated in the Declaration of Helsinki (2013) and the WHO/CIOMS Guidelines (2016). The NEJM article forms part of an observable trend of moral backsliding that needs to be recorded. In this paper, considering traditional medical research ethics under the impact of the Covid-19 pandemic and its ramifications and effects, and with a particular focus on the highly vulnerable populations and countries of sub-Saharan Africa, I make some relevant remarks. My arguments here are anchored in my observations as a moral philosopher though limited by my lack of expertise in any of the branches of medical science.
\end{abstract}

Keywords: Covid-19, Africa, WHO, medical research ethics, vulnerability, vaccines, treatments.

\section{Introduction}

My remarks and arguments in this paper are sparked-off by, but not limited to, a WHO Ad Hoc expert group article published in the highly influential The New England Journal of Medicine, titled:"Placebo-Controlled Trials of Covid-19 Vaccines - Why We Still Need Them"(1).

Author: Godfrey B. Tangwa (gbtangwa@yahoo.com), University of Yaounde 1, Cameroon, and Cameroon Bioethics Initiative (CAMBIN), Simbok, Yaounde, CAMEROON.

To cite: Tangwa GB. Covid-19, the WHO, and the apparent collapse of traditional medical research ethics. Indian J Med Ethics. 2021 Apr-Jun; 6(2) NS: 130-135.DOI: 10.20529/IJME.2021.028.

Published online first on April 13, 2021.

Manuscript Editors: Ruth Macklin, Amar Jesani.

Peer reviewer: An anonymous reviewer.

(c) Indian Journal of Medical Ethics 2021
The Covid-19 (SARS-CoV- 2) pandemic has had a highly disruptive and disorienting effect on human life and wellbeing in all parts of the globe. The pandemic seems to mark a turning point in the history of our world, particularly the history of the African continent, which has been the origin of several previous epidemics later declared to be pandemics (2). Since the pandemic broke out, the same procedures and attempted solutions - lockdown, social distancing, hand washing, mask wearing, triaging for scarce medical resources applied in the high income countries have been prescribed even if not completely applied in Africa, with little consideration for contextual differences and specificity. Mask wearing, for instance, may be strongly prescribed but is hardly applicable in areas where the temperatures soar above 40 degrees Celsius most of the day, as is the case in many parts of sub-Saharan Africa. And, while no one disputes the importance of frequent hand washing with soap under running water, how is this to be achieved where there is no water, let alone pipeborne water, and where people daily trek several kilometres in search of water? Furthermore, it takes only casual observation to realise that social distancing, quarantine, or individual isolation of any type, is a prescription almost impossible to attain in African socio-cultural settings. So, none of the prescribed so-called non-pharmaceutical public health measures against Covid-19 is realistically completely applicable in African settings, although this is not an argument for completely abandoning them.

We must never forget the Holocaust, which was the "inflection point" in the development of bioethics and medical research ethics $(3,4)$. The Holocaust marked the active participation of the scientific and medical communities of one of the most advanced countries in the world (Germany) in genocide. This culminated, after the Nuremberg Trials (1945-1947), in the elaboration of the Nuremberg Code (1947), the Declaration of Helsinki (1948) and later the WHO/CIOMS Guidelines (1992), the last of which specifically focused on the application of these regulations in the developing world. Some elements of these regulatory documents are purely scientific, others practical or procedural and others ethical (5). Among all the elements that go into the formulation of any of these guidelines, only the ethical element or impulse is timeless and universalisable; all the rest are amenable to changes justifiable by advances in scientific knowledge, techniques and allied 
procedures. We can isolate the universal and timeless element if, for example, we ask the question: "What is it about the Holocaust that makes it universally and timelessly horrendous?" The horror we feel about the Holocaust is moral horror; it has nothing to do with the fact that its main perpetrators were Germans and its victims Jews, but rather simply that both the agents and the victims of the terrible events of the Holocaust were human beings. The level of science and technology that obtained at the time in this regard is of no consequence. No particular expertise beyond moral sensibility and sensitivity, which are part and parcel of being human, is required to realise this. In the absence of moral consciousness, even a hall full of experts is not likely to arrive at morally agreeable decisions. I have tried making this argument over the years in various ways and contexts (6-8) without any palpable evidence that it has been noticed.

The chief subverters of moral sensibility and sensitivity are the will to have power and control, and one's individual interests or desire for personal gain/advantage. It is therefore always important to distinguish the science from the ethics and to keep in mind that, while bad science may rightly be said to be, ipso facto, unethical, good science in itself is not necessarily ethical; scientific procedures and techniques, no matter how sophisticated and approbated by the highest expertise, must be subjected to rigorous ethical appraisal, by ethics review committees, for example.

The Covid-19 pandemic is perhaps one of the worst health events in human history from the point of view of its speed, breadth of spread, and fatality rate, and its disruption of economic and normal everyday activities in all parts of the world. As extraordinary challenges demand extraordinary responses, medical practices and medical research must act accordingly in efforts to contain the epidemic and especially to save human lives. However, while ethical rules of procedure may be stretched to their elastic limits in facing such challenges, they cannot be broken or set aside without incurring moral blame. We can talk about a "new normal" for science and technology at various points, but there is never a new normal for ethics, although that does not imply that our moral consciousness is static. In spite of the rapid evolution of the medical sciences, the injunction "primum non nocere" (above all do no harm), adopted by medical physicians as the first principle of their practice, is one that, from the ethical point of view, must equally guide medical research at all times in all its dimensions. Of the four cardinal principles of ethics - autonomy, beneficence, non-maleficence and justice - non-maleficence is the most basic for, even if we are to fail in achieving good, we can and should avoid doing harm. Avoiding the possibilities of doing harm must therefore be at the forefront of medical research; and deliberately infecting a healthy individual with a pathogen, for example, is an act incompatible with such a procedural rule, no matter what circumstantial or contextual conditions may seem to justify it $(9,10)$.

There is an urgent need during a deadly infectious pandemic to provide firm but flexible (as opposed to cast-iron) safeguards; so that both medical practice and research may ethically be carried out within those limits. In all human activities, ethics must be the permanent referee, showing red (stop!), yellow (pause and think!) or green (go ahead!) cards as appropriate. Ethics is often assisted in this role by the law and by customs, traditions, and practices, depending on the context, paradigm, and system in operation.

Opportunism and exploitation are ethically problematic at all times, but this is particularly the case during a pandemic. It is ethically questionable to use a deadly pandemic as the occasion to advance profit-driven science and medicine, permitting a fraction of the global population to enrich itself and to enhance its power and control over the rest of humanity. It is hard to assert with confidence that this has not been the case with Covid-19. The incredible speed with which vaccines became ready for deployment, the failure so far to pinpoint the exact origin of the virus, the creation of artificial scarcity to trigger a scramble by countries, the hoarding of vaccine supplies by some high-income countries, the secrecy surrounding the costing and probable financial benefits, the silence over redress for possible related harms, the inability of poor countries to access the vaccines despite all the solidarity and equitable access rhetoric, are all indicative of the power of the profit motive in monopolistic capitalist commerce. The comfortable marriage between global medicine and open market commerce and processes (11) remains a problematic we must never tire of addressing and re-addressing.

\section{Global response to Covid-19}

The global response to Covid-19 has been heavily tilted towards vaccines to the neglect of treatments; in fact, from the very onset of the epidemic we've hardly been hearing about treatments but only about vaccines, as if vaccines are the treatment. This is an ethical issue and one of the reasons that the efforts in many African countries where plant-based treatments have been discovered against the virus have been all but ignored. In Cameroon, for instance, the multiple cures (discussed below) cannot all be dismissed as placebo effects and, if treatments were taken more seriously, should have attracted the intervention of the $\mathrm{WHO}$, even if the procedural methods of African traditional medicine do not follow the canons of Western allopathic medicine. The first intuitive reaction of anyone (including any vaccinologist) who catches an illness, even a highly infectious one, is to seek a cure or treatment, not a prophylactic against future infection, even if such can be described as "immunotherapeutic". It is difficult for many ordinary people to comprehend why the global response to Covid-19 has been so disproportionately focussed on vaccines as against treatments. This is one putative reason that conspiracy theories and even misinformation against vaccines have gained believers (12). And the speed with which candidate vaccines, even granted the advantages of advanced scientific methods and techniques, seem to be ready for mass application, remains rather questionable. 
Compared to the traditional steps and stages of medicine and vaccine development, one gets the impression that, with Covid-19, vaccine developers have opted for extensive experimentation on human beings of candidate products whose medium and long term effects have not yet thoroughly been investigated. The Covid-19 vaccines being deployed around the world are said to have gone through all the traditional stages of vaccine development, which usually take years, if not decades, in accelerated form. This evokes some incredulity, especially as the technologies that might make such speed possible are very new. Moreover, some of the vaccines are already proving not to be as effective as at first claimed, on the basis of new variants of the virus (13) and in some instances, vaccinations have been temporarily paused as a result of adverse side effects (14). Thus, these appear more like investigational products than vaccines as we have known them. This is a major ethical issue.

However, we have not witnessed any debates reminiscent of those in the late 1990s and early 2000s over such issues as use of placebos in clinical trials, or post-trial access to treatments. The existence of ethical, if not legal, frameworks ostensibly meant to protect human subjects of medical research in many countries nowadays would give the impression that research ethics has greatly evolved. But, if in spite of those structures, deliberately infecting human beings with dangerous pathogens looks like becoming a norm, it becomes hard to unequivocally assert such ethical progress.

\section{The African situation}

Africa's well known multiple vulnerabilities pre-Covid-19 have remained intact within the pandemic although, in terms of Covid-related deaths, Africa (excepting the Republic of South Africa) has fared better, against all expectations and predictions (15). At the beginning of the pandemic, confident predictions were made of an oncoming catastrophe when it would get to Africa but that has not yet come to pass, and the death toll is significantly lower in Africa than in the other regions of the world. Given all the impediments to complying with non-pharmaceutical public health measures, this situation is likely due to a number of factors including environmental and climatic factors $(16,17)$ and reliance on herbal treatments (18). The Republic of South Africa (RSA) is a special case within the African continent. The cases of Covid-19 in the RSA, and the high death toll, has been very similar to cases in the Western world, for reasons that need to be explored. The RSA enthusiastically participated in the testing of some candidate vaccines (19) but does not seem to have derived any post-trial benefits from such participation, owing to failure to negotiate post-trial access and benefit-sharing mechanisms (20). That also is an ethical issue.

Regarding herbal treatments against Covid-19, Cameroon, hot on the heels of Madagascar, has come up with several plantbased remedies that seem to cure the infection $(21,22)$. In April 2020, Madagascar had officially launched a herbal medicine, COVID Organics (CVO), developed by the Malagasy Institute of
Applied Research, from the Artemisia plant, well known for its anti-malarial properties, that it claimed both prevents and cures Covid-19 $(23,24)$. Although the WHO was prompt in dismissing the claim that CVO cures Covid-19, insisting that there is as yet no cure for the disease (25), other African countries were enthusiastic in placing orders for the medicine from Madagascar $(26,27)$ and South Africa offered to carry out a confirmatory scientific analysis of the herbal mixture (24).

Whenever the WHO declares that there is no treatment for a disease, what it clearly means is that there is as yet no drug approved by the US Food and Drug Administration (FDA) or duly licensed in any part of the industrialised developed world. For an organisation with a global mandate, this is not good enough, unless one assumes that globalisation is no more and no less than Westernisation (7). Traditional herbal medicine does not, of course, follow the canons of western allopathic medicine but both are evidence-based in the broad sense that a good medicine is one that treats the disease or alment against which it is directed. Furthermore, the WHO seems to be under the subtle influence and control of for-profit medical research organisations with a clear preference for research on vaccines, possibly on account of their high profitability. That is a major ethical issue.

\section{The particular case of Cameroon}

In Cameroon, there is a plethora of plant-based therapies for Covid-19 $(21,28)$. Notable among these are the following:

1. A well-known traditional healer claims to have a cocktail, composed of a tea, a sirop and a powder made from plants, which eliminates all the symptoms of Covid-19.

2. Another traditional healer claims to have a plant-based remedy "Covid Cure" which is both curative and preventive, and of which he has distributed about 1,000 doses and cured approximately 400 Covid- 19 cases.

3. A third herbalist has developed "Corovitaz", composed of vitamins, anti-bacteria, anti-parasites aninflammatories. He does not give an exact number but claims to have cured hundreds of Covid-19 patients.

4. A Cameroonian trained in allopathic western medicine and based in the USA, where he runs a research laboratory, claims to have discovered a "magic cure", called "Stop Corona" against Covid-19.

5. The last case here is that of a Catholic Archbishop in Cameroon, who announced the successful treatment of Covid-19 positive patients with an herbal mixture, "Elixir COVID" and "Adsak COVID". It is avowed that over 5,000 patients, among them some who were already on ventilators in state hospitals, have been successfully treated, including several healthcare workers.

Each of the above claimants of a cure for Covid-19 has reported about their remedy to the governmental authorities and in the media, in the hope that it would be investigated 
and officially approved. But, not surprisingly, the government, as well as the majority of western-trained medical scientists, is highly reticent if not dismissive of these claims, preferring to wait for instructions or cues from the international community and the WHO. If science is evidence-based, then the scientific merits of these herbal medicines cannot be brushed aside but ought to be investigated with rigour in all objectivity. Why do they seem to work, and what is it in each of them that makes them produce the observed effects? The scientific and medical merit of efficacious herbal remedies ought to be investigated and in fact ought to form one of the main focus areas of the country's efforts in the face of Covid-19. This will require collaboration between modern western allopathic medicine and African traditional medicine. Such collaboration is not only possible but currently going on, although too slowly for what is really called for in a pandemic situation.

Cameroon is remarkable for its biodiversity - plant, animal and human - and the vast majority of its inhabitants still live close to nature; and this plethora of possible cures is a fruit of that biodiversity, combined with a relatively natural mode of living. This is a very good thing for Cameroon which, otherwise, presents perhaps the worst global case scenario for tackling Covid-19 as both the government and the populations, steeped in an on-going deadly genocidal civil war, have shown no seriousness with preventive measures against Covid-19.

\section{The WHO: An agency for global health or an arm of global westernisation?}

The WHO is perhaps the most important agency of the United Nations with a global mandate whose importance is evident and acknowledged by all and sundry. All around the world, governments, especially ministries of public health, healthcare providers and medical researchers, listen to the WHO and quote its prescriptions and recommendations with finality. For these reasons, the WHO needs to be not only highly professional in its actions and pronouncements, but also transparently fair to all the different global communities and competing interests in global health. Unfortunately, the WHO seems to fall short of these ideals $(29,30)$.

Seemingly anticipating the evolution of events with Covid-19, the WHO had issued directives shortly after its outbreak outlining "criteria for ethical acceptability" of human challenge studies - deliberate infection of a healthy individual with a virus $(31,32)$ - for any candidate vaccine against Covid-19. Was this ethics, calculated at protecting human subjects of medical experimentations, or rather calculative expert support of vaccine developers? Deliberately infecting a human being with a pathogen is an action that, though not completely impossible under certain thinkable specific conditions, merits extensive ethical debate

Some authors (Vaswani et al 2020) have gone even further to make a strong case for including uneducated and illiterate persons in deliberate pathogen infection studies (33). Medical research ethics thus seems to have come under the tyranny of experts who know how to technicalise, rationalise and ethically appear to justify any scientifically convenient procedure in the interest of global for-profit medical research. Their altruistic philanthropic rhetoric, sedating platitudes and ubiquitous use of the word "ethical" are just a dressing accompanying the text. With such a trend, medical research ethics clearly seems to stand in need of rebooting.

Maani N, et al. (2021) in their recent article on the new WHO Foundation, express this concern more pointedly: "If the current pandemic has taught us anything, it is that prevention is better than the cure, and that the WHO forms a crucial element of coordinating and informing that prevention globally. The WHO cannot be seen to be sacrificing its independence or impartiality to commercial determinants of health in order to access greater resources. The current signs from the WHO Foundation are troubling..." (30). We should all be troubled! In the recent past, before the outbreak of Covid19, the WHO has conducted or facilitated the conduct of appreciable vaccine research in Africa. But some of such research, as in the case of Ebola in Guinea and the Democratic Republic of the Congo, raised a number of ethical questions including post-trial access, vaccine rationing and the use of placebo in the control arm $(34,35)$. These are ethical issues that the WHO must make sure to address in future vaccine research in Africa, so as to avoid any form of ethics dumping (36).

\section{Vaccination lobbies and campaigns in Africa}

There is a strong lobby for Covid-19 vaccinations in Africa even though none of the vaccines that are in the market have been sufficiently tested on the continent and, as already mentioned, seem to be still under testing world-wide against emerging new mutations, strains, variations or varieties of the virus, necessitating, inter alia, introduction of boosters; and it is not yet quite clear how much protection, for how long on what category of patients, each vaccine confers on its recipients. That notwithstanding, the vaccination lobby in Africa is taking on the contours of a strong campaign; it is coming at a time many people are getting to hear for the first time, not only about the advantages/disadvantages of vaccines but also about the commercial aspects regarding who actually owns which of the vaccines and their comparative costs and profits.

Proponents and defenders of Covid-19 vaccines testing in Africa are, arguably, mostly eminent scientists and research funding beneficiaries. The gist of the recurring thrust of their several arguments for vaccine testing is that Africa bears $25 \%$ of the global burden of disease but conducts only $2 \%$ of clinical trials; that Africa's virtual absence from the "clinical trials map" is a big problem; that it is vital for Africans to take part in vaccine trials or else the aim of finding a vaccine that works worldwide and not just for the richer nations would be jeopardised; that Africa risks being 'locked out' from the world to continue in its legacy of exclusion, inequality and poverty; that different circumstances and genetic profiles affect how a 
vaccine may work, and Africa needs to take part in vaccine tests to ensure having a vaccine that works in Africa $(37,38)$.

These are well-resourced and articulated arguments by those who probably have a vested stake in the vaccine they envisage being tested in Africa and they therefore sound like planned project drives, if not rehearsed product propaganda. A detail in these arguments is worth further consideration. If genetic makeup and circumstances are so important for a vaccine, that would seem to be a very good reason why each country or region that shares the same gene pool, with a similar level of material affluence and existential conditions should be engaged in developing their own vaccine?

\section{Different healthcare systems}

There need to be different healthcare systems around the globe, each harmonised with its particular environment, instead of the current situation where the healthcare system of the industrialised developed world is being globalised as a consequence of colonialism, domination and exploitation. The current dilemmas of rationing in the face of Covid-19 as well as the challenges of vaccine development and distribution are highly accentuated because of a system in which healthcare is inextricably dovetailed with commerce, for-profit procedures and the attendant morally insensitive forces, since self-interest and the profit motive are very subversive of moral sensitivity and sensibility (11). An important question that remains is whether the institutions and traditions of medicine and healthcare as they have been known in the Western world itself are really morally compatible with its market thinking, theory and practice. But this important consideration evidently seems to have been overtaken by the sheer momentum of things. In short, it seems that liberal capitalist economic thinking has overwhelmed everything else in the Western world and is in the process of overwhelming the rest of the world through colonial hegemony and globalisation.

It is odd that many African countries, without basic hygiene and sanitation, without any primary healthcare system, without even a glance at their own traditional healthcare systems and the values on which over $80 \%$ of their populations depend, focus their attention and public resources on imitative mimicry of high-tech medicine developed elsewhere and not yet domesticated on African soil. High-tech medicine is a patent of the industrialised developed world, harmonised with its general culture and traditional medicine from which it evolved, and those outside of that world cannot fully participate in it except as colonised, dependent, subjugated and exploited people. The imperative alternative is to acquire and use science and technology to modernise African traditional medicine and, if need be, to develop it to high-tech medicine. Otherwise, the best that is achievable is what is observable, namely, that the main beneficiaries of hightech medicine in Africa are, have been, and will continue to be the small number of people who are privileged, economically or otherwise, to have access to these high-tech advances in medicine and science. Inequalities amongst African populations whereby a small minority is able to live a highincome world lifestyle in a low-income world setting cannot be explained without reference to the phenomenon of colonisation, its legacies and hegemony. But then, where does that leave the African masses? There is need for drastic change in Africa.

\section{Conclusion}

Covid-19 is one of the most devastating epidemics in human history. It has affected all continents of the world, all countries and all human communities although in different ways and to varying degrees, thereby truly earning the title of a pandemic. Different peoples in different parts of the world who survive the epidemic must learn what lessons they can learn from the event to move forward with their lives. Africa is the least technologically developed of the continents and has been a colonised and exploited continent for several centuries. Even in the face of Covid-19, Africa seems to have been looked upon by many in the rest of the world mainly as the continent where Covid-19 vaccine tests could speedily and cost-effectively be carried out, for the benefit of the rest of the world. But, of course, Covid-19 vaccine tests have been carried out in other parts of the world and can also be carried out in Africa under suitable ethical and other conditions. A recent study on vaccine hesitancy in Cameroon (39) is instructive regarding some of what needs to be done to improve vaccination enthusiasm in Africa.

The promoters and campaigners of Covid-19 vaccines testing in Africa, conceived and developed elsewhere, have all characteristically ignored or downplayed the remarkable potential treatments of the disease in several African countries with plant-based medicines. Africa at this moment in its chequered history more urgently needs decolonisation than a vaccine; which is not to say that it does not also urgently need a Covid-19 vaccine. Colonisation is one of the greatest crimes against humanity whose destructive effects have so far refused to go away. Genuine decolonisation in Africa should be followed by transforming the continent into a place where all black people and all people of African descent can feel completely at home; where all human beings, no matter from where they are coming, can feel at home, because of the pervasive spirit and practice of the BihWir/Ubuntu philosophy (40).

\section{Acknowledgment}

I thankfully acknowledge the assistance of Nchangwi S Munung in checking, ordering, and arranging the references of this article.

\section{References}

1. WHO Ad Hoc Expert Group on the Next Steps for Covid-19 Vaccine Evaluation. Placebo-Controlled Trials of Covid-19 Vaccines - Why We Still Need Them. N Engl J Med. 2021 Jan 14; 384(2):e2-e3. Epub 2020 Dec 2.

2. Fenollar F, Mediannikov O. Emerging infectious diseases in Africa in the 21st century. New Microbes New Infect. 2018 Sep 21;26:S10-S18. Doi: 10.1016/j.nmni.2018.09.004.

3. Caplan AL. The meaning of the Holocaust for bioethics. Hastings Cent Rep. 1989;19(4):2-3. 
4. Gallin S, Bedzow I. Holocaust as an Inflection Point in the Development of Bioethics and Research Ethics. In: Iphofen R, editor. Handbook of Research Ethics and Scientific Integrity. Chatelaillon Plage France: Springer, Cham; 2019. p. 1-20.

5. Tangwa GB. Between universalism and relativism: a conceptual exploration of problems in formulating and applying international biomedical ethical guidelines.J Med Ethics. 2004;30(1):63-7.

6. Tangwa GB. Moral status of embryonic stem cells: perspective of an African villager. Bioethics. 2007;21(8):449-57.

7. Tangwa GB. Globalisation or Westernisation? Ethical concerns in the whole bio-business. Bioethics. 1999;13(3-4):218-26.

8. Tangwa GB. Rights and rationing in health care: Some random considerations from the African context. In: Elements of African Bioethics in a Western Frame. Mankon, Bamenda: Langaa Research \& Publishing CIG; 2010. p. 70-82.

9. Kahn JP, Henry LM, Mastroianni AC, Chen WH, Macklin R. Opinion: For now, it's unethical to use human challenge studies for SARS-CoV-2 vaccine development. Proceedings of the National Academy of Sciences of the United States of America. 2020 Oct 29;117(46):2853842. Doi: $10.1073 /$ pnas. 2021189117

10. Macklin R. Human Challenge Studies for a COVID-19 Vaccine: Ethical Quandaries. Albert Einstein College of Medicine Blog. 2020 May 15[cited 2020 May 25]. Available from: http://blogs.einstein.yu.edu/ human-challenge-studies-for-a-covid-19-vaccine-ethical-quandaries/

11. Callahan D, Wasunna AA. Medicine and the Market: Equity v. Choice. Johns Hopkins University Press; 2006.334 p.

12. Burki T. The online anti-vaccine movement in the age of COVID-19. Lancet Digit Health. 2020;2(10):e504-e5.

13. Madhi SA, Baillie V, Cutland $C L$, Voysey $M$, Koen $A L$, Fairlie $L$, et al. Efficacy of the ChAdOx1 nCoV-19 Covid-19 Vaccine against the B.1.351 Variant. N Engl J Med. 2021 Mar 16. Doi: 10.1056/NEJMoa2102214

14. Wise J. Covid-19: European countries suspend use of OxfordAstraZeneca vaccine after reports of blood clots. BMJ. 2021;372:n699.

15. Tangwa GB, Munung NS. COVID-19: Africa's relation with epidemics and some imperative ethics considerations of the moment. Res Ethics. 2020 Jun;16(3-4):1-11. Doi:10.1177\%2F1747016120937391

16. WHO Afro. Social, environmental factors seen behind Africa's low COVID-19 cases. Brazzaville, Republic of Congo: WHO; 2020 Sep 24 [cited 2021 Apr 10]. Available from: https://www.afro.who.int/news/ social-environmental-factors-seen-behind-africas-low-covid-19-cases.

17. CSIR. South Africa. The role of weather, climate and environmental factors in the spread oF COVID-19. 2020 Jul 29 [cited 2021 Apr 10]. Available from: https://www.csir.co.za/role-weather-climate-andenvironmental-factors-spread-covid-19

18. Orisakwe OE, Orish CN, Nwanaforo EO. Coronavirus disease (COVID-19) and Africa: Acclaimed home remedies. Scientific African. 2020;10:e00620.

19. Medical Brief. Two more COVID-19 vaccine candidates to be trialled in SA. Updated 2020 Aug 12 [cited 2021 Feb 15]. Available from: https:// www.medicalbrief.co.za/archives/two-more-covid-19-vaccinecandidates-to-be-trialled-in-sa/.

20. Moodley K, Rossouw T. South African COVID-19 vaccine trials hold key lessons for future partnerships. Conversation. 2021 Feb 10 [cited 2021 15 February]. Available from: https://theconversation.com/southafrican-covid-19-vaccine-trials-hold-key-lessons-for-futurepartnerships-154676.

21. Kindzeka ME. Hundreds rush for popular cleric's herbal COVID 'cure' in Cameroon. VOA News. 2020 May 2[cited 2021 Feb 15]. Available from: https://www.voanews.com/covid-19-pandemic/hundreds-rushpopular-clerics-herbal-covid-cure-cameroon 2020

22. Sina NK. COVID-19 : Archbishop Samuel Kleda proposes a herbal remedy. CRTV. 2020 Apr 29[cited 2021 Feb 15] Available from: http:// www.crtv.cm/2020/04/covid-19-archbishop-samuel-kleda-proposesa-herbal-remedy/

23. Africa News. Madagascar's coronavirus cure hits the shelves. Africa.com. 2020 Apr[cited 2021 Feb 15] Available from: https:// africa.com/madagascars-coronavirus-cure-hits-the-shelves/2020

24. Finnan D. South Africa steps up to help Madagascar test herbal cure for Covid-19. RFI 2020 May 8[cited 2021 Feb 15]. Available from: http://www.rfi.fr/en/africa/20200508-south-africa-steps-up-to-helpmadagascar-test-herbal-cure-for-covid-192020 08 May 2020. [cited 2020].

25. Vaughan A. No evidence 'Madagascar cure' for covid-19 works, says WHO. New Scientist. 2020 May 15[cited 2021 Feb 15]. Available from: https://www.newscientist.com/article/2243669-no-evidencemadagascar-cure-for-covid-19-works-says-who/\#ixzz6NXGXHYXP

26. Rabary L. Madagascar coronavirus herbal mix draws demand from across Africa despite WHO misgivings. Reuters. Updated 2020 May 8 [cited 202115 February]. Available from: https://www.reuters.com/ article/us-health-coronavirus-madagascar-idUSKBN22K1HQ.

27. Medical Brief. Tanzania joins the list of African countries importing Madagascar's COVID-19 'cure' Medical Brief. Updated 2020 May 06[cited $2021 \mathrm{Feb} 15]$. Available from:https://www.medicalbrief.co.za/ archives/tanzania-joins-the-list-of-african-countries-importingmadagascars-covid-19-cure/2020

28. La Nouvelle Expression. Traitement du coronavirus : les solutions camerounaises font-elles peur: La Nouvelle Expression. 2020 Jun 06[cited 2021 Feb 15]. [French]. Available from: https:// actucameroun.com/2020/06/09/traitement-du-coronavirus-lessolutions-camerounaises-font-elles-peur/

29. Tangwa GB, Afolabi MO. Global emerging pathogens and the (prescriptive) role of the World Health Organization. In: Tangwa GB, Abayomi A, Ujewe SJ, Munung NS, editors. Socio-cultural Dimensions of Emerging Infectious Diseases in Africa: An Indigenous Response to Deadly Epidemics. Cham: Springer International Publishing; 2019. p. 135-42.

30. Maani N, Van Schalkwyk MCl, Petticrew M, Ralston R, Collin J. The new WHO Foundation - global health deserves better. BMJ Global Health. 2021 Feb 1;6(2):e004950.

31. Jao I, Marsh V, Che Chi P, Kapulu M, Hamaluba M, Molyneux S, et al. Deliberately infecting healthy volunteers with malaria parasites: Perceptions and experiences of participants and other stakeholders in a Kenyan-based malaria infection study. Bioethics. 2020;34(8):81932.

32. Jamrozik E, Littler K, Bull S, Emerson C, Kang G, Kapulu M, et al. . Key criteria for the ethical acceptability of COVID-19 human challenge studies. Geneva: WHO Working Group for Guidance on Human Challenge Studies in COVID-19; 2020 [cited 2021 May 31] p. 18. Available from: https://europepmc.org/article/MED/33341309? singleResult=true

33. Vaswani V, Saxena A, Shah SK, Palacios R, Rid A. Informed consent for controlled human infection studies in low- and middle-income countries: Ethical challenges and proposed solutions. Bioethics. 2020 Aug;34(8):809-18.

34. Médecins Sans Frontières. WHO rationing Ebola vaccine as outbreak still not under control in Democratic Repulic of Congo. MSF. 2019 Sep 23[cited 2020 May 31] Available from https:// www.doctorswithoutborders.org/what-we-do/news-stories/news/ who-rationing-ebola-vaccines-outbreak-still-not-under-control

35. Cohen J, Kupferschmidt K. Ebola vaccine trials raise ethical issues. Science. 2014;346(6207):289.

36. Tangwa GB, Browne K, Schroeder D. Ebola Vaccine Trials. In: Schroeder D, Cook J, Hirsch F, Fenet S, Muthuswamy V, editors. Ethics Dumping: Case Studies from North-South Research Collaborations. Cham: Springer International Publishing; 2018. p. 49-60.

37. Makoni M. COVID-19 vaccine trials in Africa. Lancet Respir Med. 2020 Nov;8(11):e79-e80.

38. Singh JA. The case for why Africa should host COVID-19 candidate vaccine trials. J Infect Dis. 2020 Aug 1;222(3):351-5.

39. Dinga JN, Sinda LK, Titanji VPK. Assessment of vaccine hesitancy to a COVID-19 vaccine in Cameroonian adults and its global implication. Vaccines. 2021 Feb 19;9(2):175.

40. Tangwa GB. Bioethics and Ubuntu, The transformative global potential of an African concept. In: Lauer $\mathrm{H}$, Yitah $\mathrm{H}$, editors. The Tenacity of Truthfulness: Philosophical Essays in Honour of Mogobe Bernard Ramose. Pretoria: EARS Publishing Company; 2019. p. 239-49. 